\title{
Growth environment and organ specific variation in in-vitro cytoprotective activities of Picea mariana in PC12 cells exposed to glucose toxicity: a plant used for treatment of diabetes symptoms by the Cree of Eeyou Istchee (Quebec, Canada)
}

Ashleigh D. Downing ${ }^{1 \dagger}$, Hoda M. Eid ${ }^{2,3+}$, Andrew Tang ${ }^{4}$, Fida Ahmed ${ }^{4}$, Cory S. Harris ${ }^{4}$, Pierre S. Haddad ${ }^{2}$, Timothy Johns ${ }^{5}$, John T. Arnason ${ }^{4}$, Steffany A. L. Bennett ${ }^{6}$ and Alain Cuerrier ${ }^{1 *}$ (D)

\begin{abstract}
Background: The Cree of Eeyou Istchee (James Bay area of northern Quebec) suffer from a high rate of diabetes and its complications partly due to the introduction of the western lifestyle within their culture. As part of a search for alternative medicine based on traditional practice, this project evaluates the biological activity of Picea mariana (Mill.) Britton, Sterns \& Poggenb. needle, bark, and cone, in preventing glucose toxicity to PC12-AC cells in vitro (a diabetic neurophathy model) and whether habitat and growth environment influence this activity.

Methods: Three different organs (needle, bark, and cone) of P. mariana were collected at different geographical locations and ecological conditions and their $80 \%$ ethanolic extracts were prepared. Extracts were then tested for their ability to protect PC12-AC cells from hyperglycaemic challenge at physiologically relevant concentrations of $0.25,0.5$, 1.0 and $2.0 \mathrm{\mu g} / \mathrm{mL}$. Folin-Ciocalteu method was used to determine the total phenolic content of P. mariana extracts.

Results: All extracts were well-tolerated in vitro exhibiting $L_{50}$ of $25 \mu \mathrm{g} / \mathrm{mL}$ or higher. Extracts from all tested organs showed a cytoprotective concentration-dependent response. Furthermore, the cytoprotective activity was habitat- and growth environment-dependent with plants grown in bog or forest habitats in coastal or inland environments exhibiting different cytoprotective efficacies. These differences in activity correlated with total phenolic content but not with antioxidant activity. In addition, this paper provides the first complete Ultra-Performance Liquid Chromatographyquadrupole time-of-flight (UPLC-QTOF) mass spectrometry analysis of Picea mariana's bark, needles and cones.

Conclusions: Together, these results provide further understanding of the cytoprotective activity of Canadian boreal forest plants identified by the Cree healers of Eeyou Istchee in a cell model of diabetic neuropathy. Their activity is relevant to diabetic peripheral neuropathic complications and shows that their properties can be optimized by harvesting in optimal growth environments.
\end{abstract}

Keywords: Traditional medicine, PC12-AC, UPLC-QTOF, DPPH, Phenolics, Stilbenes, Glucose toxicity

\footnotetext{
* Correspondence: alain.cuerrier@umontreal.ca

${ }^{\dagger}$ Ashleigh D. Downing and Hoda M. Eid contributed equally to this work.

${ }^{1}$ Jardin botanique de Montreal, Institut de recherche en biologie végétale,

Université de Montréal, 4101, rue Sherbrooke Est, Montreal, (Québec) H1X

2B2, Canada

Full list of author information is available at the end of the article
}

(c) The Author(s). 2019 Open Access This article is distributed under the terms of the Creative Commons Attribution 4.0 International License (http://creativecommons.org/licenses/by/4.0/), which permits unrestricted use, distribution, and reproduction in any medium, provided you give appropriate credit to the original author(s) and the source, provide a link to the Creative Commons license, and indicate if changes were made. The Creative Commons Public Domain Dedication waiver (http://creativecommons.org/publicdomain/zero/1.0/) applies to the data made available in this article, unless otherwise stated. 


\section{Background}

In recent years, there has been increasing recognition of the deteriorating health status of Canadian First Nation peoples with respect to chronic diseases $[1,2]$. Among the chronic diseases afflicting these populations, diabetes has stood out as a literal epidemic [3-5]. Low levels of compliance due to treatment incompatibility have led to high levels of severe complications in these populations [3, 6-8].

Picea mariana (Mill.) Britton, Sterns \& Poggenb., commonly known as black spruce or Inaatuk in Cree has been used as a folk remedy for skin and soft tissues conditions and as analgesic [9-11]. Poultice of inner bark has been applied for infected inflammations [10]. Infusion of bark has been used for pain relief [9] and the gum soaked in hot water has been used in burn dressing or smeared on painful areas of the body [11]. Decoction of needles has been applied to cure skin sores and to speed wound healing [12].

The proposed solution to the rejection of western medication, as part of the CIHR Team in Aboriginal Antidiabetic Medicines (TAAM), is to make traditional treatment options readily available alongside conventional treatment $[7,13]$. To accomplish this goal, semi-structured ethnobotanical surveys have been conducted in Misstisini, Whapmagoostui [14, 15], Waskaganish and Nemaska [16]. Using the Syndromic Importance Value (SIV) calculation, $P$ mariana emerged in ethnobotanical surveys as a top ranking plant [15]. Specifically, it is mentioned as a possible treatment for symptoms related to diabetic neuropathy (pain, loss of sensation which increases risk of wounds to the extremities, slow-healing wounds and greater risk of wound infections due to weakened immune response) [14, 15].

To date, only antidiabetic activities of a cone extract have been investigated. The extract showed high antioxidant activity, insulin sensitizing and glitazone-like effects. It also conferred protection to PC12 cells, a model of peripheral neuronal precursors from high glucose insult [14, 17, 18]. Given these data and that extracts from needles of Picea glauca (Moench) Voss (a closely related species) also protect PC12 cells from hyperglycemic challenge [19], we compared the cytoprotective efficacy of extracts prepared from three different organs (needle, bark and cone) of $P$. mariana collected at different geographical locations and ecological conditions. Our primary goal was to establish whether cytoprotective activity was dependent upon habitat and growth environment and to elucidate what the ideal collection conditions might be for this plant. Here we describe how cytoprotective and mitogenic activities differ between extracts sampled from coastal and inland populations (Waskaganish to Mistissini) in areas where bog (low land) meets forest (high land). Six of nine Eeyou Istchee communities across a varied northern Quebec landscape have already participated in ethnobotanical studies that may lead to the incorporation of traditional pharmacopeia into clinics. Communities are situated inland (Mistissini,
Nemaska, Oujé-Bougoumou) or on the coast of James or Hudson Bay (Waskaganish, Wemindji, and Whapmagoostui). The evaluation of local harvesting is essential to determine whether plant organs will yield similar benefits under different growing conditions, knowing especially that this region is vast. The development of this research question has come directly from the elders of Eeyou Istchee who emphasized the importance of plant selection and regional variation.

\section{Methods \\ Plant material}

P. mariana organs (needle, bark and cone) were harvested in proximity to the Cree communities of Waskaganish, Nemaska and Mistissini located within the $50^{\circ}$ and $51^{\circ} \mathrm{N}$ latitudes (Quebec, Canada). Twenty-one populations were selected (Fig. 1). Plants were harvested at the boundaries of high land (forest) and low land (bog) to enable collection from two distinct habitats (bog or forest) within the same geographical growth environment (measured as proximity to the James Bay coast). Growth environment was considered coastal if it was $<50 \mathrm{~km}$ from the coast and inland if further. To ensure that habitats were distinct, bog stands were defined as trees growing in $>30 \mathrm{~cm}$ sphagnum moss. Forests were defined as having trees growing in organic soil with $<20 \mathrm{~cm}$ sphagnum moss ground cover. Separate populations had to be at least $5 \mathrm{~km}$ apart and in most cases were much further in order to sample across all three communities. Needles and bark were harvested from 10 trees within a $50 \mathrm{~m}$ radius for each habitat. Cones were collected from the same trees when available however, they were often unreachable or not present. All bulk materials were air dried upon collection and dried to completion in a plant drier at $40{ }^{\circ} \mathrm{C}$ prior to shipment. All samples were collected and dried within a few weeks. The dried samples were extracted at the University of Ottawa. Voucher specimens were deposited at the Marie-Victorin Herbarium (MT) located at the Jardin botanique de Montréal (PM001 to PM040).

\section{Extract preparation}

Twenty populations of needles were extracted. Pooled samples were made by weighing out $2 \mathrm{~g}$ of material from each tree $(10 \mathrm{x})$ resulting in a total of $2 \mathrm{~g}$ per location. The $2 \mathrm{~g}$ sample was placed in a magic bullet blender (Homeland Housewares) along with $20 \mathrm{~mL}$ of $80 \%$ ethanol $(10$ $\mathrm{mL} / \mathrm{g}$ material) and collected in $50 \mathrm{~mL}$ Fisher falcon tubes. After blending, the sample was sonicated for $20 \mathrm{~min}$ and the first extraction mixture was stored at $4{ }^{\circ} \mathrm{C}$ for 1 week. The ethanol extract was centrifuged for $15 \mathrm{~min}$ at $1811 \mathrm{~g}$ and the liquid supernatant was removed by pipette and stored at $4{ }^{\circ} \mathrm{C}$. Ten $\mathrm{mL}$ of fresh $80 \%$ ethanol was added to the pellet, sonicated and stored at $4{ }^{\circ} \mathrm{C}$. The second supernatant was then removed and added in the same fashion 


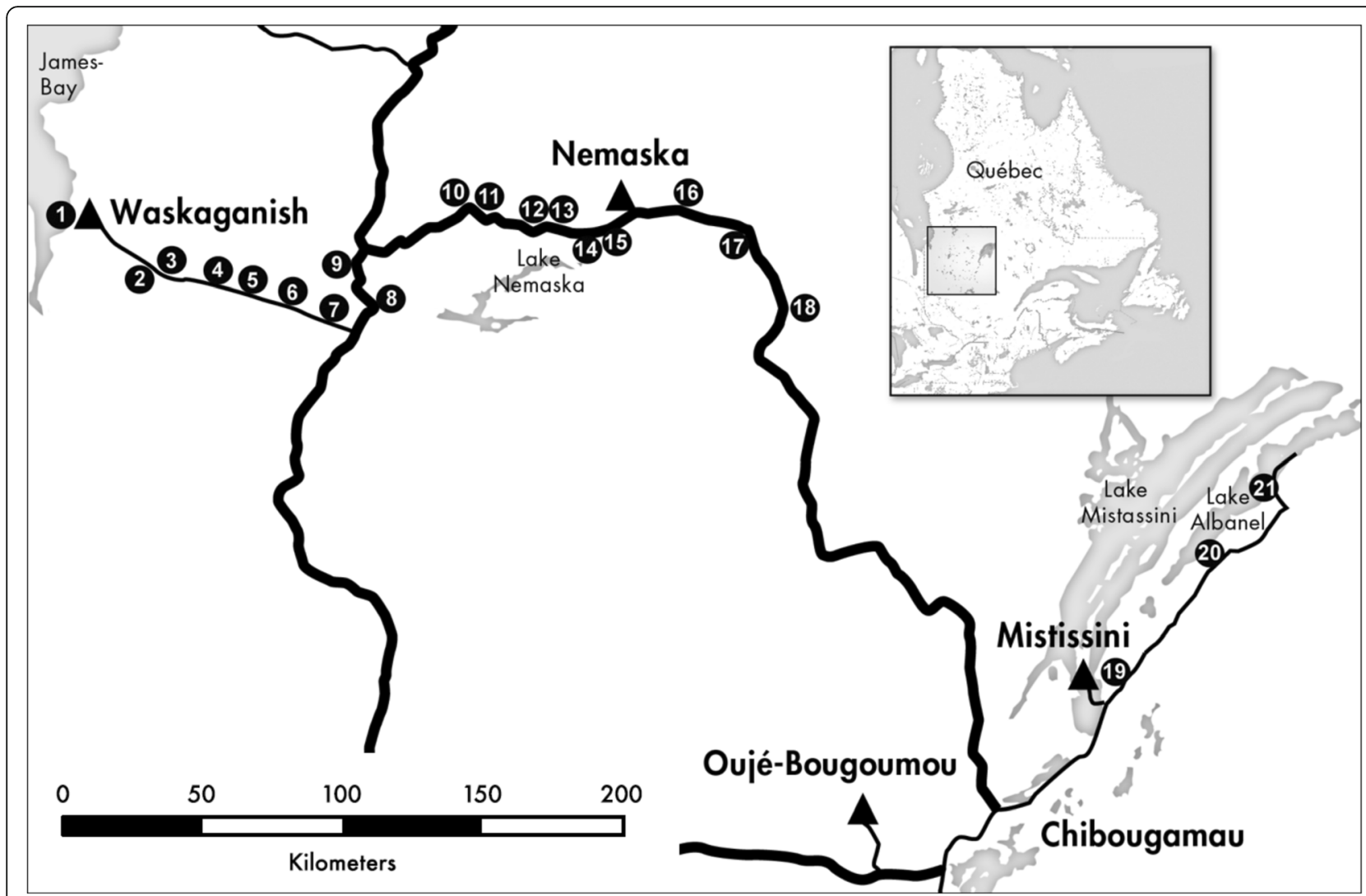

Fig. 1 Map representing plant sampling locations (white number in black circle). The markers represent both the high and low land locations since they were next to each other. For example the circle labelled "3" represents bog and forest populations. At this location materials for B3N, B3B, B3C, F3N, F3B and F3C were collected. Cree communities are represented by a $\boldsymbol{\Delta}$ symbol. This map was simplified using photoshop, from "The Far North Nunavik and James Bay" tourist map which was sourced from the Base de données géographiques et administratives du Québec (BDGA)

as the first. Alcohol was then removed from the pooled supernatant using a Labconco Centrivap (Fisher Scientific, Ottawa, Canada) at $40^{\circ} \mathrm{C}$ for $72 \mathrm{~h}$. The alcohol-free extract was lyophilized using a freeze dryer (Edwards Pirani 501, Fisher Scientific, Ottawa, Canada) for $72 \mathrm{~h}$. The result was a dry stable extract that was homogenized and stored in a freezer at $-20^{\circ} \mathrm{C}$. Nine of the 20 populations were included for the analysis of bark extracts. It was necessary in the case of bark and cone to grind samples in a Wiley mill ( $2 \mathrm{~mm}$ mesh) tree by tree before evenly pooling the populations. As before $2 \mathrm{~g}$ of the pooled sample was processed using the same protocol as for the needles. In the case of cones, however, only five extracts were prepared by pooling 4 trees per population due to a lack of material. A total of 64 different extracts were prepared ( 20 needle bog, 20 needle forest, 9 bark bog, 9 bark forest and 6 cone bog $=64$ ).

\section{Cell culture and bioactivity assays}

PC12-AC cells of the clonal derivate of the rat pheochromocytoma cell line (American Type Culture Collection (ATCC), Manassas, VA, USA) [20] were maintained in $10 \mathrm{~cm}$ dishes with $10 \mathrm{~mL}$ complete media (RPMI, 10\% horse serum, $5 \%$ new born calf serum) at $37^{\circ} \mathrm{C}$ with $5 \%$ atmospheric $\mathrm{CO}_{2}$. Complete media provided a normoglucose environment (11 $\mathrm{mM}$ glucose). Bioactivity was assessed as previously described [19, 21]. To elicit glucose toxicity (hyperglycemia), complete medium was replaced with this same serum-free media supplemented with $150 \mathrm{mM}$ glucose and $0.025 \%$ Bovine Serum Albumin (BSA). Following $96 \mathrm{~h}$ (hyperglycemia assays) of treatment, the cell proliferation reagent WST-1 (Roche Diagnostics, Laval, Quebec, Canada) was added to each well and incubated for $60 \mathrm{~min}$ before spectrophotometric analysis at $420 \mathrm{~nm}$ (formazan) and $620 \mathrm{~nm}$ [22]. Cultures were compared to cell-free treatment media incubated for the same period. Cell number per well was calculated from standard curves derived from wells containing known cell densities. Standardization allowed data to be compared across replicates. For $\mathrm{LD}_{50}$ assessments, each extract was tested at eight different concentrations in quintuplicate over two separate experiments $(n=15$ per concentration). For hyperglycemia assays, maximal test concentrations were at least one log concentration below their $\mathrm{LD}_{50}$ in normoglucose media. Each extract was tested at four different concentrations in a minimum of triplicate measures $(n=3-6)$. Data from control cultures 
were combined across plates $(n=54)$. Percent viability was calculated as follows: \% viability = cell number (treat-

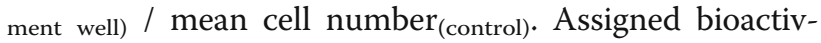
ities (cytotoxic, cytoprotective, or mitogenic) based on this screen were validated by direct assessment of viable cell number using Trypan Blue hemocytometer counts.

\section{DPPH antioxidant assay}

Extracts were tested for their radical scavenging activity using the 1,1-diphenyl-2-picryl-hydrazyle radical (DPPH) test as in [23]. Ascorbic acid (AA) was used as a control to generate a standard curve for the calculation of its $\mathrm{IC}_{50}$ : the concentration where $50 \%$ of the DPPH radical is quenched by AA. The following Least squares regression equation was used $\left[\hat{y}_{i}-y_{0}=\frac{\sum_{i}\left\{\left(x_{i}-x_{0}\right)\left(y_{i}-y_{0}\right)\right\}}{\sum_{i}\left(x_{i}-x_{0}\right)^{2}}\left(x_{i}\right.\right.$ $\left.\left.-x_{0}\right)\right]$ in order to determine the line of best fit for the $\mathrm{IC}_{50}$ calculation where $\mathrm{y}=$ absorbance at $517 \mathrm{~nm}$ and $\mathrm{x}=$ concentration in $\mathrm{ppm}$. This method is employed over the traditional method of discerning the linear portion of the line visually and is a more accurate method of extrapolation. Pure catechin and epicatechin compound was used as positive controls for comparison to crude plant extract samples. Extracts identified as having bioactivity in both screening paradigms and following direct validation were tested to determine whether antioxidant activity correlated with cytoprotection or mitogenicity in hyperglycemic media. Three independent assays were run with samples tested in duplicate.

\section{Total phenolics test}

The Folin-Ciocalteu method was used as previously described [24], and later modified by Harris et al. (2008). A standard curve was constructed using dilutions of quercetin (Sigma Aldrich Co) at concentrations of 1.0, 0.75, 0.5, $0.25,0.10$, and $0.05 \mathrm{mg} / \mathrm{mL}$. Eight hundred micro liters of Folin reagent was added to $160 \mu \mathrm{L}$ of sample with $540 \mu \mathrm{L}$ $7.5 \% \mathrm{NaHCO}_{3}$ and stored in the dark for $2 \mathrm{~h}$. Absorbance was recorded at $725 \mathrm{~nm}$ using a spectrophotometer (Molecular Devices SpectraMax 5, Molecular Devices, Sunnyvale, CA, USA). Fifteen milligrams of crude extract was resolubilized in $80 \%$ ethanol at $10 \mathrm{mg} / \mathrm{mL}$ inside $1.5 \mathrm{~mL}$ centrifuge tubes. The samples were then vortexed until totally dissolved and sonicated for $15 \mathrm{~min}$. These extracts were dyed using the same procedure and the concentration determined using the standard curve.

\section{Ultra-performance liquid chromatography-quadrupole time-of-flight mass spectrometry (UPLC-Q-TOF)}

Samples were prepared by dissolving $40 \mathrm{mg}$ of crude extract in $1 \mathrm{~mL}$ of methanol (Sigma Aldrich, St Louis, MO, USA). A standard of $600 \mu \mathrm{L}$ of resveratrol $(1 \mathrm{mg} /$
$\mathrm{mL}$ ) (Sigma) was added to $500 \mu \mathrm{L}$ of extract to make a total volume of $1100 \mu \mathrm{L}$. The mixture was filtered through a $0.2 \mu \mathrm{m}$ PTFE nylon membrane filter (Chromatographic Specialties Inc., Brockville, ON, Canada) and sonicated for $5 \mathrm{~min}$ before injection.

Analyses were undertaken on an Acquity UPLC coupled with XevoG2 QTOF system (Waters Inc., Milford, MT, USA). UPLC analyses were performed on a Waters Acquity system. Separations were performed on a BEH C18 $1.7 \mu \mathrm{m}, \quad 2.1 \times 100 \mathrm{~mm}$ column (part \#186002352; serial \#02113226415705, LANSET\# General Purpose $2.1 \times 100 \mathrm{BEH}$ ) connected with a VanGuard pre-column $2.1 \times 5 \mathrm{~mm}$. Mobile phases: $\mathrm{A}$, water $+0.1 \%$ formic acid, and B-acetonitrile $+0.1 \%$ formic acid (Fisher Optima LC-MS). Flow rate $0.8 \mathrm{ml} / \mathrm{min}$ (back pressure at starting conditions $=10,000 \mathrm{PSI}$ ). Column temperature, $65{ }^{\circ} \mathrm{C}$, sample temperature $4{ }^{\circ} \mathrm{C}$. Mobile phase composition of $\mathrm{B}, 0-2$ min $2 \%$ B isocratic, $2-5$ min linear gradient $2-100 \%$ B, $5-6$ min $100 \%$ B isocratic, $6-8$ min return to initial mobile phase composition of $2 \% \mathrm{~B}$ isocratic. A $5 \mu \mathrm{L}$ injection was performed through a $10 \mu \mathrm{L}$ loop followed by strong wash $200 \mu \mathrm{L}(50 \%$ acetonitrile $+50 \%$ water) and weak wash $600 \mu \mathrm{L}(10 \%$ acetonitrile $+90 \%$ water). Q-TOF was operated in positive and negative electrospray ionization modes. MassLynx software (Version 4.1) was used to acquire high and low energy spectra in $\mathrm{MS}^{\mathrm{e}}$ ESI+ and MS ${ }^{\mathrm{e}}$ ESI- modes within the mass range of 100-1500 Da. Lock mass was set with Leucine Enkephalin $\mathrm{C}^{12}$ at $556.2615 \mathrm{Da}[\mathrm{M}+\mathrm{H}]^{+1}$ and 554.261 Da $[\mathrm{M}-\mathrm{H}]^{-1}$, source and desolvation temperatures were $150^{\circ} \mathrm{C}$ and $500{ }^{\circ} \mathrm{C}$ respectively. Cone gas and desolvation gas (nitrogen) were set at 50 and $1200 \mathrm{~L} / \mathrm{hr}$ ). The identification of the compounds is based on matching the molecular ion acquired in low fragmentation setting and the major fragments acquired in high fragmentation setting within the mass accuracy of 5 PPM.

\section{Results \\ Percentage yield}

Upon extraction, 18, 25 and 30\% of dried needles, bark and cone were sequestered.

\section{Bioactivity}

$\mathrm{LD}_{50}$ values for all extracts were $25 \mu \mathrm{g} / \mathrm{mL}$ or higher. Consequently, each extract was screened at $0.25,0.5,1$ and $2 \mu \mathrm{g} / \mathrm{mL}$ for capacity to alter glucotoxicity in vitro (Tables 1, 2, 3, Figs. 2, 3, Additional files 1-3: Figures S1-S3). Maximal concentrations of extracts were at least one log concentration below their $\mathrm{LD}_{50}$ in normoglucose media. Glucotoxicity (high glucose, HG) reduced the number of viable cells to $56.8 \%$ that of normoglucose controls (C) (Figs. 2 and 3). Samples were stated as biologically active if at least two or more concentrations elicited a statistically significant change in viable cell number. Compounds that 
Table 1 Bioactivity of Picea mariana needle extracts in PC12-AC grown in hyperglycemic media

\begin{tabular}{|c|c|}
\hline Extract IDa & Bioactivity in hyperglycemic media ${ }^{b}$ \\
\hline $1 F N$ & Cytoprotective \\
\hline $1 \mathrm{BN}$ & None \\
\hline $2 \mathrm{FN}$ & None \\
\hline $2 \mathrm{BN}$ & None \\
\hline $3 \mathrm{FN}$ & None \\
\hline $3 B N$ & None \\
\hline $4 \mathrm{FN}$ & None \\
\hline $4 \mathrm{BN}$ & None \\
\hline $5 F N$ & None \\
\hline $5 B N$ & None \\
\hline $6 \mathrm{FN}$ & Cytoprotective \\
\hline $6 \mathrm{BN}$ & Cytoprotective \\
\hline 7FN & None \\
\hline 7BN & Cytoprotective \\
\hline $8 \mathrm{FN}$ & Mitogenic \\
\hline $8 \mathrm{BN}$ & Mitogenic \\
\hline 9FN & None \\
\hline 9BN & Cytoprotective \\
\hline $10 \mathrm{FN}$ & Cytoprotective \\
\hline $10 \mathrm{BN}$ & None \\
\hline $11 \mathrm{FN}$ & None \\
\hline $11 \mathrm{BN}$ & None \\
\hline $13 \mathrm{FN}$ & None \\
\hline $13 \mathrm{BN}$ & None \\
\hline $14 \mathrm{FN}$ & None \\
\hline $14 \mathrm{BN}$ & None \\
\hline $15 \mathrm{FN}$ & None \\
\hline $15 \mathrm{BN}$ & None \\
\hline $16 \mathrm{FN}$ & Cytoprotective \\
\hline $16 \mathrm{BN}$ & None \\
\hline $17 F N$ & Cytoprotective \\
\hline $17 \mathrm{BN}$ & Cytoprotective \\
\hline $18 \mathrm{FN}$ & Cytoprotective \\
\hline $18 \mathrm{BN}$ & Cytoprotective \\
\hline $19 F N$ & None \\
\hline $19 B N$ & Cytoprotective \\
\hline $20 \mathrm{FN}$ & None \\
\hline 20BN & None \\
\hline $21 \mathrm{FN}$ & Cytoprotective \\
\hline $21 \mathrm{BN}$ & None \\
\hline
\end{tabular}

${ }^{a}$ The extract ID code defines the growth environment (Area\#1-21, Fig. 1), habitat ( $B$ Bog or $F$ forest) and organ ( $N$ needle). For example, 1FN is an extract prepared from needles collected in a forest habitat at location \#1. Populations are listed in ascending order from coastal west (1) to inland east
(21) with forest (F) and bog (B) populations next to one another for comparison

${ }^{b}$ Bioactivity was classified comparing a $96 \mathrm{~h}$ treatment in hyperglycemic (150 $\mathrm{mM}$ ) serum-free media. Viable cell number following extract treatment was established using the WST-1 assay compared to standard curves of known cell number. Vehicle control was $0.1 \%$ DMSO. Extracts that at two or more concentrations increased viable cell number to values significantly higher than the normoglucose controls ( $>100 \%$ ) were classified as mitogenic, those which significantly protected cells from high glucose toxicity without apparent mitogenic activity were classified as cytoprotective, and those which enhanced glucotoxicity were classified as cytotoxic. Statistics were ANOVA, post-hoc Tukey tested vs. vehicle-treated cultures in normo- or high glucose media. All concentration-response data and statistical analyses are presented in Additional file 1: Figure S1

increased viable cell number to values significantly higher than the normoglucose controls ( $>100 \%$ ) were considered mitogenic. Compounds that significantly protected cells from high glucose toxicity (56.8\%) without exceeding normoglucose viability values were considered cytoprotective; compounds that enhanced glucotoxicity at any concentration were considered cytotoxic (Tables 1, 2, 3).

We found that $50 \%$ of all organ extracts improved viability of $\mathrm{PC} 12$ cultures under hyperglycemic conditions (Tables 1, 2, 3, Additional files 1-3: Figures S1-S3). Moreover, all extracts were well-tolerated in that none of them enhanced glucose cytotoxicity. We identified 24 cytoprotective (38\% of total) and seven mitogenic (9\% of total) extracts. Two extracts (3\% of total) exhibited both concentration-dependent cytoprotective and mitogenic activities. When comparing the overall bioactivity of extracts prepared from needle, bark and cone collected in all regions and habitats, we found that protective effects were maximal at the lowest tested concentrations in all cases and were not organ-specific with the exception of bark and cone which were more effective mitogens in high glucose media than needle extracts (Tables 1, 2, 3, Additional files 1-3: Figures S1-S3, Fig. 2).

\section{Regional variation}

A primary concern of the TAAM team is to provide laboratory data assessing the importance of plant selection and regional variation emphasized by the elders and healer of the Eeyou Istchee in their traditional preparations. Their insights are crucial to ensuring that plant usage will yield similar benefits in all communities. We found that $50 \%$ of $P$. mariana needle, bark, and cone extracts (32 extracts) did not exhibit significant biological activity in our screening paradigm. To test whether extract efficacy depended upon the growth habitat where the plant had been harvested, we compared efficacy of needle and bark extracts collected in bog and forest habitats. Cone extracts were not included in this analysis as we were only able to collect cones from bog sites.

We did not detect any statistically significant differences between the bioactivities of needle and bark extracts grown in different habitats (data not shown). To test whether growth environment and habitat interacted 
Table 2 Bioactivity of Picea mariana bark extracts in PC12-AC grown in hyperglycemic media

\begin{tabular}{ll}
\hline Extract ID $^{\text {a }}$ & Bioactivity in hyperglycemic media \\
\hline $1 F B$ & Mitogenic \\
$1 \mathrm{BB}$ & Mitogenic \\
$2 \mathrm{FB}$ & Cytoprotective \\
$2 \mathrm{BB}$ & Cytoprotective \\
$3 \mathrm{FB}$ & Cytoprotective \\
$3 \mathrm{BB}$ & Cytoprotective \\
$4 \mathrm{FB}$ & Cytoprotective \\
$4 \mathrm{BB}$ & Cytoprotective \\
$5 \mathrm{FB}$ & None \\
$5 \mathrm{BB}$ & None \\
$6 \mathrm{FB}$ & Cytoprotective/Mitogenic \\
$6 \mathrm{BB}$ & Cytoprotective/Mitogenic \\
$7 \mathrm{FB}$ & Cytoprotective \\
$7 \mathrm{BB}$ & Cytoprotective \\
$11 \mathrm{FB}$ & None \\
$11 \mathrm{BB}$ & Cytoprotective \\
$14 \mathrm{FB}$ & None \\
$14 \mathrm{BB}$ & None \\
\hline
\end{tabular}

The extract ID code defines the growth environment (Area\#1-21, Fig. 1), habitat ( $B$ Bog or $F$ forest) and organ ( $B$ bark). For example, 1FB is an extract prepared from bark collected in a forest habitat at location \#1

${ }^{\mathrm{b}}$ Bioactivity was classified using a $96 \mathrm{~h}$ treatment in hyperglycemic $(150 \mathrm{mM})$ serum-free media. Viable PC12-AC cell number following extract treatment was established using the WST-1 assay compared to standard curves of known cell number. Vehicle control was $0.1 \%$ DMSO. Extracts that at two or more concentrations increased viable cell number to values significantly higher than the normoglucose controls (>100\%) were classified as mitogenic, those which significantly protected cells from high glucose toxicity without apparent mitogenic activity were classified as cytoprotective, and those which enhanced glucotoxicity were classified as cytotoxic. Samples classified with dual bioactivities (ie. Cytoprotective/Mitogenic) are possible when two concentrations satisfy our definition of one bioactivity (ie. Cytoprotective) and two other concentrations from the same sample are in another category (ie. Mitogenic). Statistics were ANOVA, post-hoc Tukey tested vs. vehicle-treated cultures in normo- or high glucose media. All concentration-response data and statistical analyses are presented in Additional file 2: Figure S2

to produce organs with different bioactivities, samples collected in different growth habitats were grouped into coastal or inland environments (Fig. 1). This analysis revealed a statistically significant interaction among growth environment, habitat, and organ bioactivity (Fig. 3) . Extracts prepared from bark collected in coastal environments showed cytoprotection where needles extracts did not (Fig. 3a and b). Moreover, in coastal-derived extracts, activity was maximal (and concentration-dependent) at low concentrations in extracts prepared from bark collected in a forest habitat (Fig. 3a) and at high concentrations in extracts prepared from bark collected in a bog habitat (Fig. 3b). At their highest percent of cell viability, extracts were even mitogenic. This interaction was organspecific. Neither growth environment nor habitat altered the cytoprotective efficacy of needle extracts (Fig. 3a-d).
Table 3 Bioactivity of Picea mariana cone extracts in PC12-AC grown in hyperglycemic media

\begin{tabular}{ll}
\hline Extract ID $^{\mathrm{a}}$ & Bioactivity in hyperglycemic media $^{\mathrm{b}}$ \\
\hline $3 \mathrm{BC}$ & Cytoprotective \\
$7 \mathrm{BC}$ & Cytoprotective \\
$11 \mathrm{BC}$ & Mitogenic \\
$12 \mathrm{BC}$ & Mitogenic \\
$14 \mathrm{BC}$ & None \\
$15 \mathrm{BC}$ & None
\end{tabular}

${ }^{\mathrm{a}}$ The extract ID code defines the growth environment (Area\#1-21, Fig. 1), habitat ( $B$ Bog or $F$ forest) and organ ( $C$ cone). For example, 1BC is an extract prepared from cones collected in a bog habitat at location \#1

${ }^{\mathrm{b}}$ Bioactivity was classified comparing a $96 \mathrm{~h}$ treatment in hyperglycemic (150 $\mathrm{mM}$ ) serum-free media. Viable cell number following extract treatment was established using the WST-1 assay compared to standard curves of known cell number. Vehicle control was $0.1 \%$ DMSO. Extracts that at two or more concentrations increased viable cell number to values significantly higher than the normoglucose controls (>100\%) were classified as mitogenic, those which significantly protected cells from high glucose toxicity without apparent mitogenic activity were classified as cytoprotective, and those which enhanced glucotoxicity were classified as cytotoxic. Statistics were ANOVA, post-hoc Tukey tested vs. vehicle-treated cultures in normo- or high glucose media. All concentration-response data and statistical analyses are presented in Additional file 3: Figure S3

\section{Total phenolics and antioxidant activity}

These data suggest that the amounts of biologically active compounds are responsible for organ-specific, habitatdependent cytoprotective bioactivities of the extracts. It has previously been suggested [17] that antioxidant activity is responsible for antidiabetic activities in $P$. mariana cone extracts. To further explore this hypothesis, we measured total phenolic content in the needle, bark and cone extracts (Fig. 4) and correlated this content with the antioxidant activity of selected extracts using the Folin-Ciocalteu total phenolics method and DPPH antioxidant tests employed in previous TAAM studies [17].

We found that the combined phenolic content was highest in cone extracts and lowest in needle. For each milligram of extract, $146.5 \pm 4.2 \mu \mathrm{g}$ (needles), $270.3 \pm$ $13.9 \mu \mathrm{g}$ (bark) and $398.7 \pm 48.8 \mathrm{l} \mu \mathrm{g}$ (cone) were phenolic compounds (Fig. 4).

$\mathrm{PH}$ antioxidant assays were completed on 14 selected extracts and plotted with respect to phenolic content (Fig. 5). A significant correlation between antioxidant activity and total phenolic content was detected $\left(r^{2}=0.63\right.$, $p<0.05$, Fig. 5).

Total phenolic content positively correlated with bioactivity $\left(r^{2}=0.30, p=0.05\right.$, Fig. 6 , Tables $\left.1,2,3\right)$. Antioxidant activity, however, was not correlated with bioactivity $\left(r^{2}=0.046, p=0.460\right.$, Fig. 7$)$. Taken together, these results suggest that, while the phenolic content of organ extracts prepared from plants harvested in different habitats and growth environments likely underlies bioactivity, the oxyradical scavenging capacity of these phenolics is not the primary mechanisms of action. 


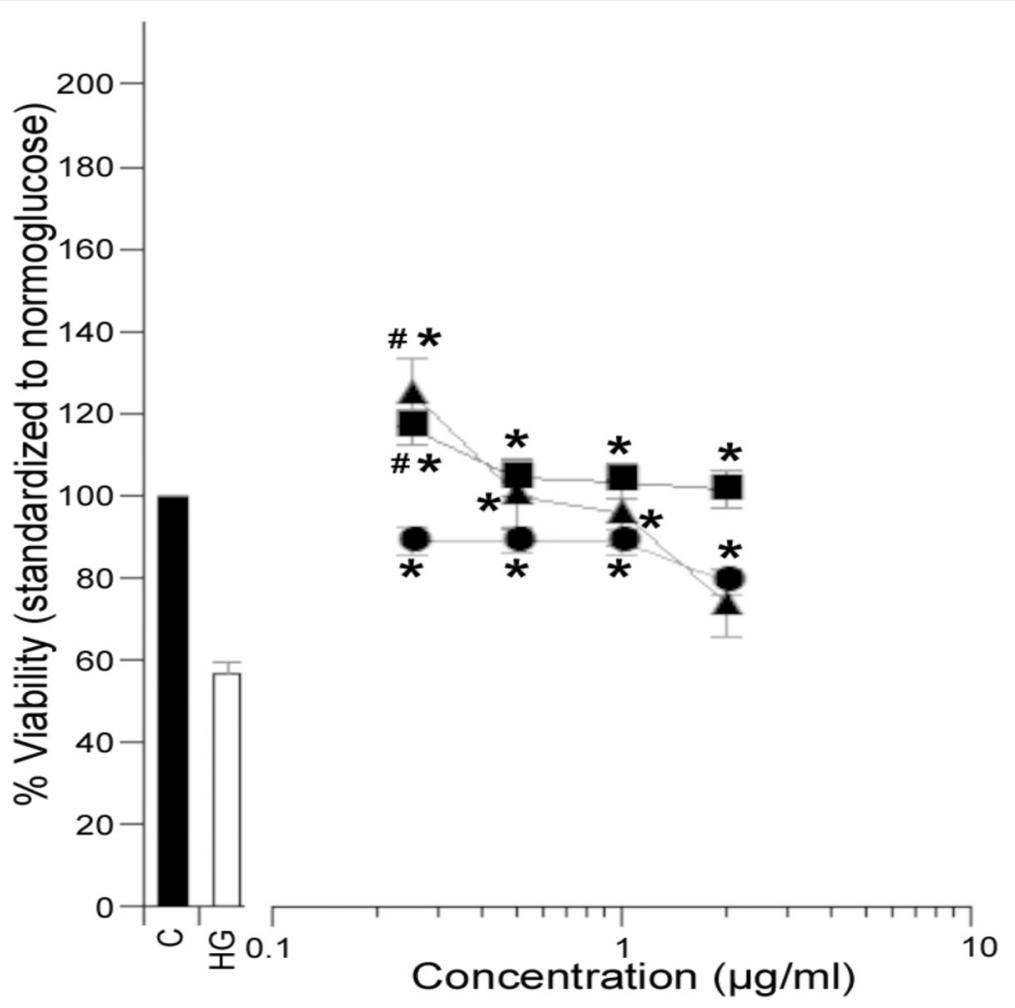

Fig. 2 Comparison of cytoprotective and mitogenic activities of $P$. mariana needle $(\bullet)$, bark ( $\mathbf{a})$ and cone $(\mathbf{\Delta})$ extracts in PC12-AC grown in hyperglycemic media. MANOVA analysis was used to average all extracts based on their organ type and concentration. Significant cytoprotection (*) or mitogenic activity (\#) was afforded when Dunnett post hoc tests were $p \leq 0.05$ as compared to the normoglucose (C) and high glucose (HG) controls. All organs showed significant protection at all concentrations except cone at $2 \mu \mathrm{g} / \mathrm{mL}$ (needle $n=120$, bark $n=60$, cone $n=18$ )

\section{UPLC-QTOF analyses}

Analyses of the methanol extracts of needle, bark and cone extracts were completed by Dr. Ammar Saleem at the LANSET core facility, University of Ottawa and yielded the identification of two classes of compounds phenolics (Additional file 4: Figure S4-a) and terpenes (Additional file 4: Figure S4-b). Using the natural products data base that we have created, a total of 32 phenolic and terpene compounds were detected in $P$ mariana needle, bark and cone extracts (Table 4, Additional file 5: Figure S5a-c). All plant parts contained proanthocyanidins b6 and b3, as well as abietic acid, dehyroabietic acid and oxodehydroabietic acid. Eleven compounds were confirmed as present in needles, with an additional 10 tentatively compounds and four in trace quantities. Kaemferol-7-O- glucoside was unique to the needles. The bark contained 8 confirmed compounds and 6 tentatively present and 2 in trace quantities with picealactone $\mathrm{b}$ as a unique component. The cones have not been previously analysed and revealed 10 confirmed compounds, 7 tentatively present and 5 trace compounds. Two significant compounds here are resveratrol, with antioxidant, antidiabetic and other biological activities [25], as well as taxifolin, also an antioxidant but structurally related to quercetin, which has previously been reported to protect against oxidative stress induced apoptosis [26]. Additional information on the new UNIFI based identification system used here and based on diagnostic low and high energy spectra will be published elsewhere.

\section{Bioactivity of taxifolin}

To investigate whether taxifolin elicits cytoprotective effects and may contribute to the observed activity of cone extracts, a pure taxifolin standard (Sigma Aldrich, Oakville, $\mathrm{ON})$ was administered at increasing non-toxic concentrations $(0.8,1.6$ and $3.2 \mu \mathrm{M})$ to PC12 cells exposed to glucotoxicity (Additional file 6: Figure S6). Cytoprotection was significant at $1.6 \mu \mathrm{M}$ with nearly identical concentrationdependent response as seen for quercetin [22].

\section{Discussion}

There is a paucity of strategies effective in managing chronic pain, infection, paralysis, and loss of sensation in association with peripheral diabetic neuropathy $[8,27]$. Based on our ethnobotanical studies, we have observed that preparations from various organs of $P$. mariana are used to treat slow healing infections, sores and numbness (particularly of the extremities), all symptoms related to diabetic neuropathy. We demonstrate for the 
A

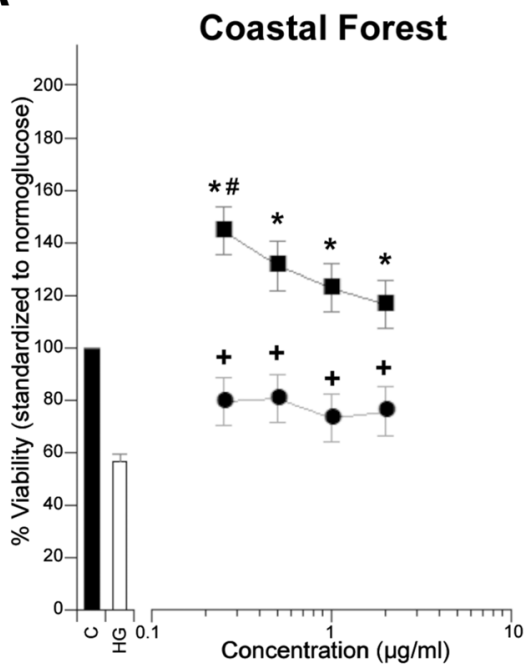

C

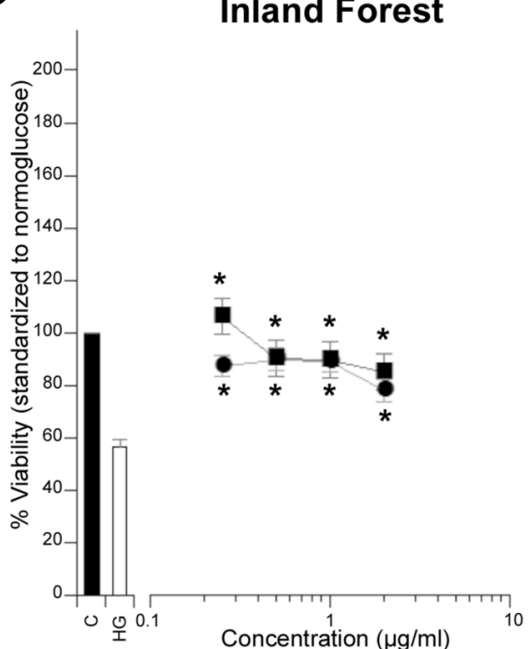

B

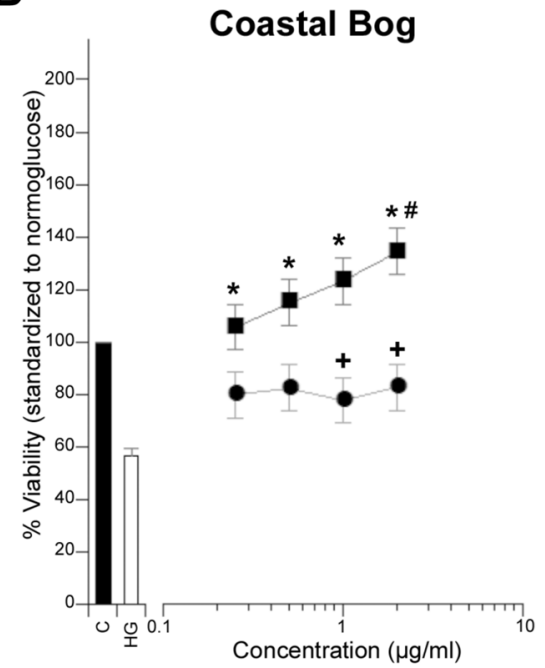

Inland Bog

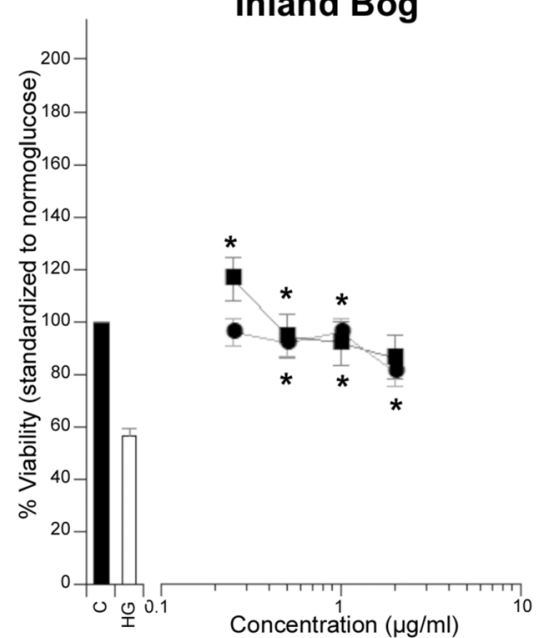

Fig. 3 Comparison of cytoprotective and mitogenic activities of $P$. mariana extracts on PC12-AC by growth environment. MANOVA analysis was used to determine the mean viability with respect to habitat (forest/ bog), growth environment (coastal/inland), organ type $($ Needle $=\bullet$, Bark $=\mathbf{m})$ and concentration $(0.25,0.50,1.00,2.00 \mu \mathrm{g} / \mathrm{mL})$ interactions. Significant protection $(*)$ or mitogenic activity (\#) was identified by Dunnett post hoc tests $(p \leq 0.05)$ by comparison to the $(\mathbf{C})$ normoglucose or $(\mathbf{H G})$ high glucose controls respectively. The same $p$ value was used to denote a significant difference between needle and bark (+) at specified concentrations. a Comparison of bark and needle extract protection in coastal forest environments (bark $n=12$, needle $n=12$ ). $\mathbf{b}$ Comparison of bark and needle extract protection in coastal bog environments (bark $n=12$, needle $n=12$ ). c Comparison of bark and needle extract protection in inland forest environments (bark $n=18$, needle $n=51$ ). d Comparison of bark and needle extract protection in inland bog environments (bark $n=18$, needle $n=45$ )

first time that $P$. mariana needles and bark are effective protectors of peripheral neuronal precursor survival when exposed to hyperglycemic conditions. We confirm the protection of cones, which was first demonstrated by our team [17]. We have also shown that harvest location can impact the cytoprotective activities of $P$. mariana, particularly for bark extracts, which tended to be more effective when obtained from inland forest populations than from coastal and inland bog populations. In a similar fashion, $[28,29]$ showed a latitudinal trend in key phenolic concentration but failed to find a correlation with bioactivity. In general, the strength of the observed activity of needle, bark and cone is correlated with the total phenolic concentration of the extracts. The one notable exception was a cone extract that was suspected to have caused oxidation, a negative response, in PC12-AC cells. The presence of too many antioxidants can actually be harmful, resulting in oxidation and therefore a decrease in cell survival. This situation was observed in preliminary DPPH tests at higher extract concentrations [30]. 


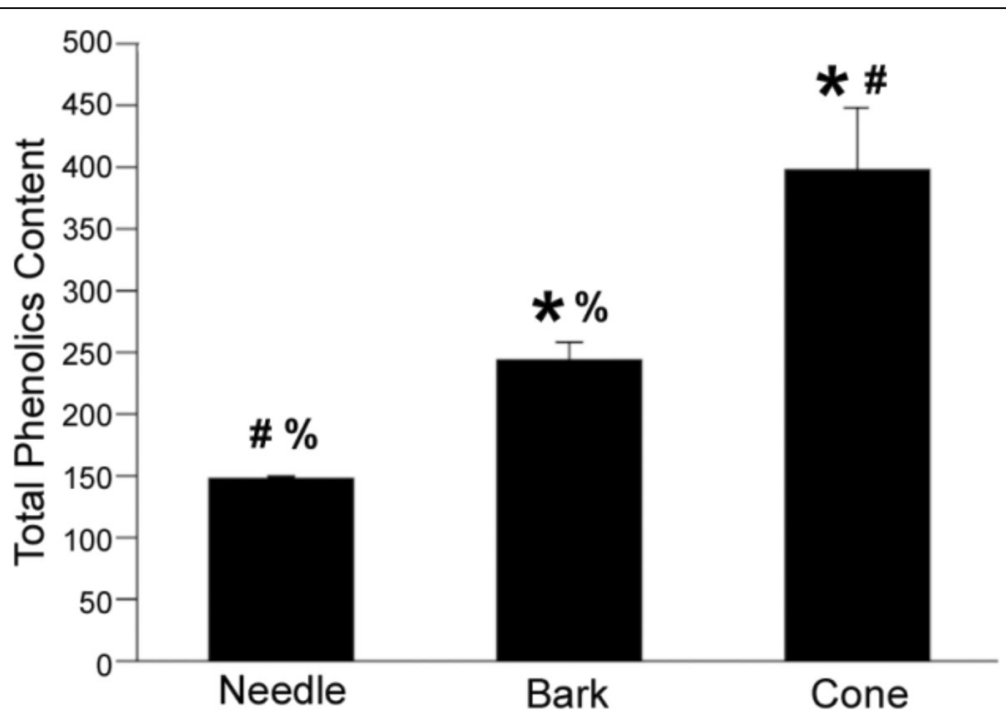

Fig. 4 Total phenolic content in terms of quercetin equivalents, of P. mariana needle, bark and cone extracts. Needle, bark and cone phenolic content was found to be significantly different from each other at $p \leq 0.05((*)=$ significantly different from needle; $(\#)=$ significantly different from bark; $(\%)=$ significantly different from cone). Cone had the highest phenolic content with $398.68(\mathrm{SE}=48.77, n=5)$, followed by bark at $244.08(\mathrm{SE}=14.51, n=18)$ and needle with $146.34 \mu \mathrm{g} / \mathrm{mg}$ extract $(\mathrm{SE}=3.78, n=40)$

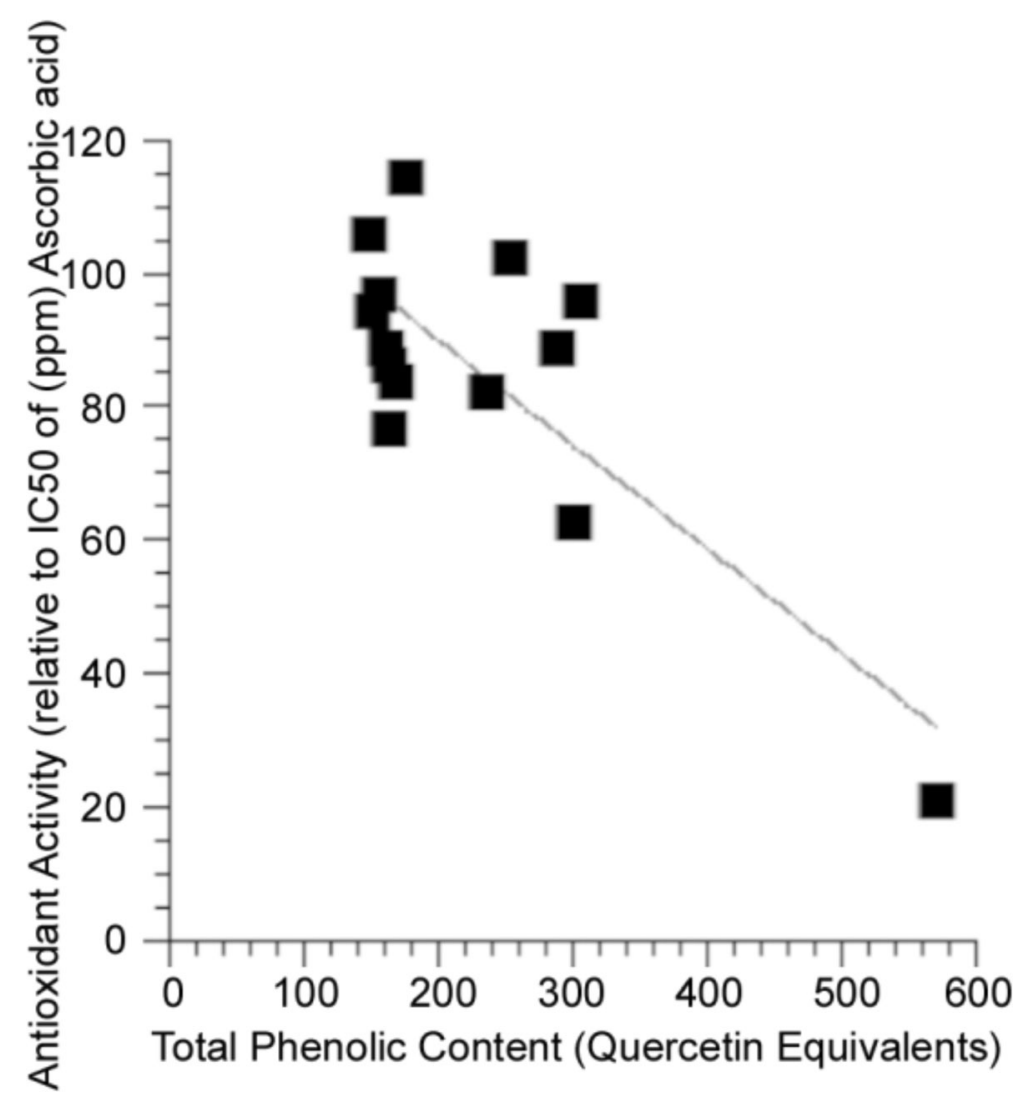

Fig. 5 Regression analysis of total phenolic content of $P$. mariana extracts with respect to antioxidant activity. Total phenolic content is measured in terms of quercetin equivalents and antioxidant activity is calculated with respect to the ascorbic acid standard curve. The trend shows that as phenolic content increases the amount of plant extract ( $\mathrm{EC}_{50}$ in $\mathrm{ppm}$ ) necessary to reach the $\mathrm{IC}_{50}$ of ascorbic acid decreases and therefore, antioxidant activity increases with increasing phenolic content $\left(r^{2}=0.63, p \leq 0.05, n=14\right)$. The data passed a normality test in order to ensure that it follows a normal distribution 


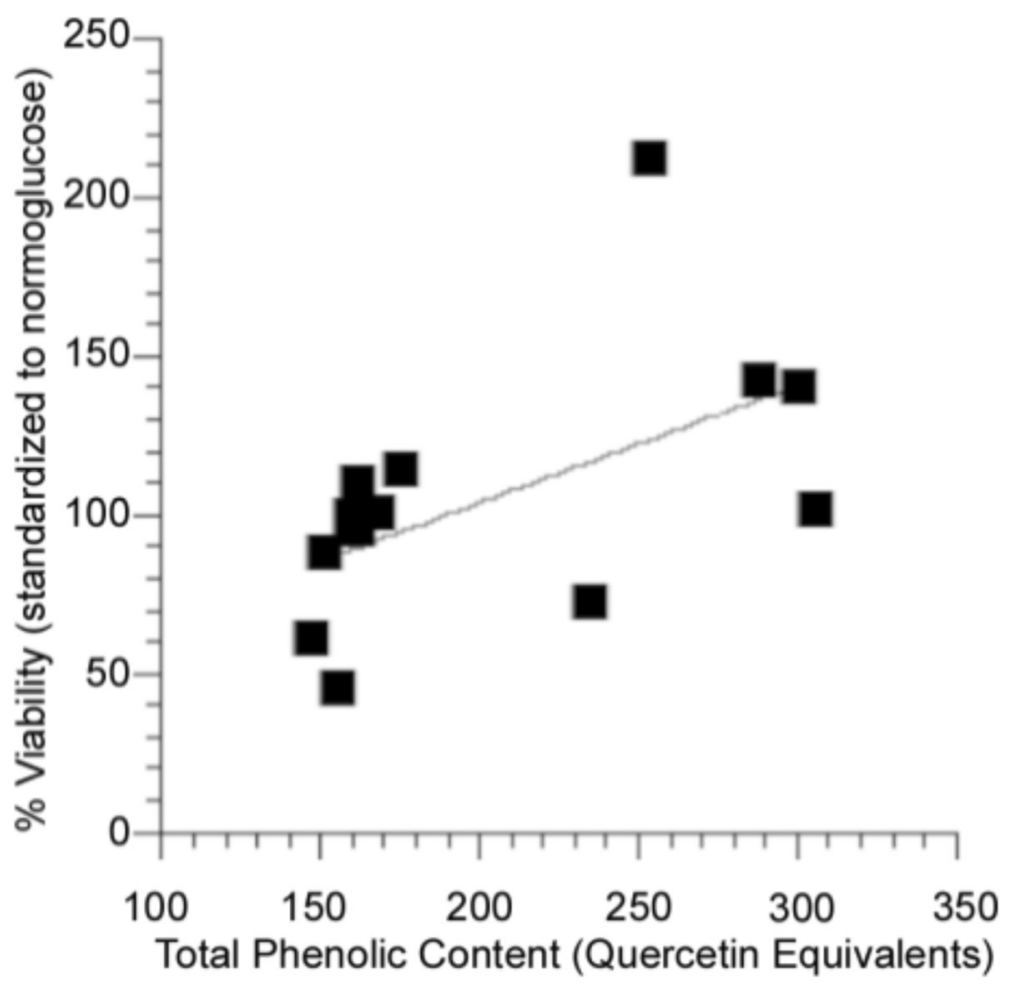

Fig. 6 Regression analysis of total phenolic content of of $P$. mariana extracts with respect to bioactivity in PC12-AC in high glucose media. The trend shows that as phenolic content increases the percent viability increases $(p \leq 0.05, n=13)$

These in vitro findings validate the importance of $P$. mariana's role as part of the Cree pharmacopoeia and underline the importance of plant selection and extract strength. In a review of Canadian aboriginal plant use, [31], it has been reported that this plant is used by the Cree to treat many ailments including heart problems, high blood pressure as well as many infectious and inflammatory conditions. To TAAM's ethnobotanical and in vitro findings $[14,15,17,32]$, we have contributed additional positive evidence that boreal plants from the Cree pharmacopoeia are capable of treating diabetes neuropathy symptoms. Specifically, we have shown at the cellular level, that this traditional medicine may be effective in the treatment of this "new" disease afflicting First Nation peoples, namely the potential to manage diabetic peripheral symptoms by protecting peripheral neurons and their precursors from hyperglycemic insult.

These results are similar to those found in Harris et al. (2008) for $P$. glauca, except that all $P$. mariana organs showed protection. In contrast to Harris et al. (2008) findings, $P$. mariana needles were generally the lowest protector against diabetic insult. One factor that should be re-examined in the case of $P$. glauca is concentration range. It may be necessary to test bark and cone at much lower concentrations than $10 \mu \mathrm{g} / \mathrm{mL}$. This is recommended because our graphs often showed a decreasing dose response from the lowest concentration to the highest (Fig. 3). Conversely, given strong correlations in both studies with total phenolic content, these data could also suggest species differences in the phenolic constituents of the different organs that underlie the cytoprotective and mitogenic bioactivities. This is a good argument for the comprehensive fractionation-based assays of organs collected at different locations and under different growth habitats in order to identify active components.

We further show that extract efficacy depends upon careful selection of plant organs depending upon growth environment and habitat as indicated by the Cree elders and healers of Eeyou Istchee. This is an important finding as it supports the efforts of traditional practitioners in ensuring equivalent benefits across communities. Variation in activity by growth environment was observable mainly for bark. In this case, we recommend inland populations or, if harvesting in proximity to the coast, to choose forest sites instead of bog sites. Conveniently, this is easier ground to navigate and a less fragile habitat. However, if a bog is the only site available for harvesting, it may be possible to achieve the same level of protection in coastal sites, for example, by simply using more plant material per treatment preparation. In the case of needles, neither growth environment nor habitat altered the cytoprotective efficacy of extracts, so no special recommendations are warranted. A lack of specificity should allow collectors to avoid overharvesting in one 


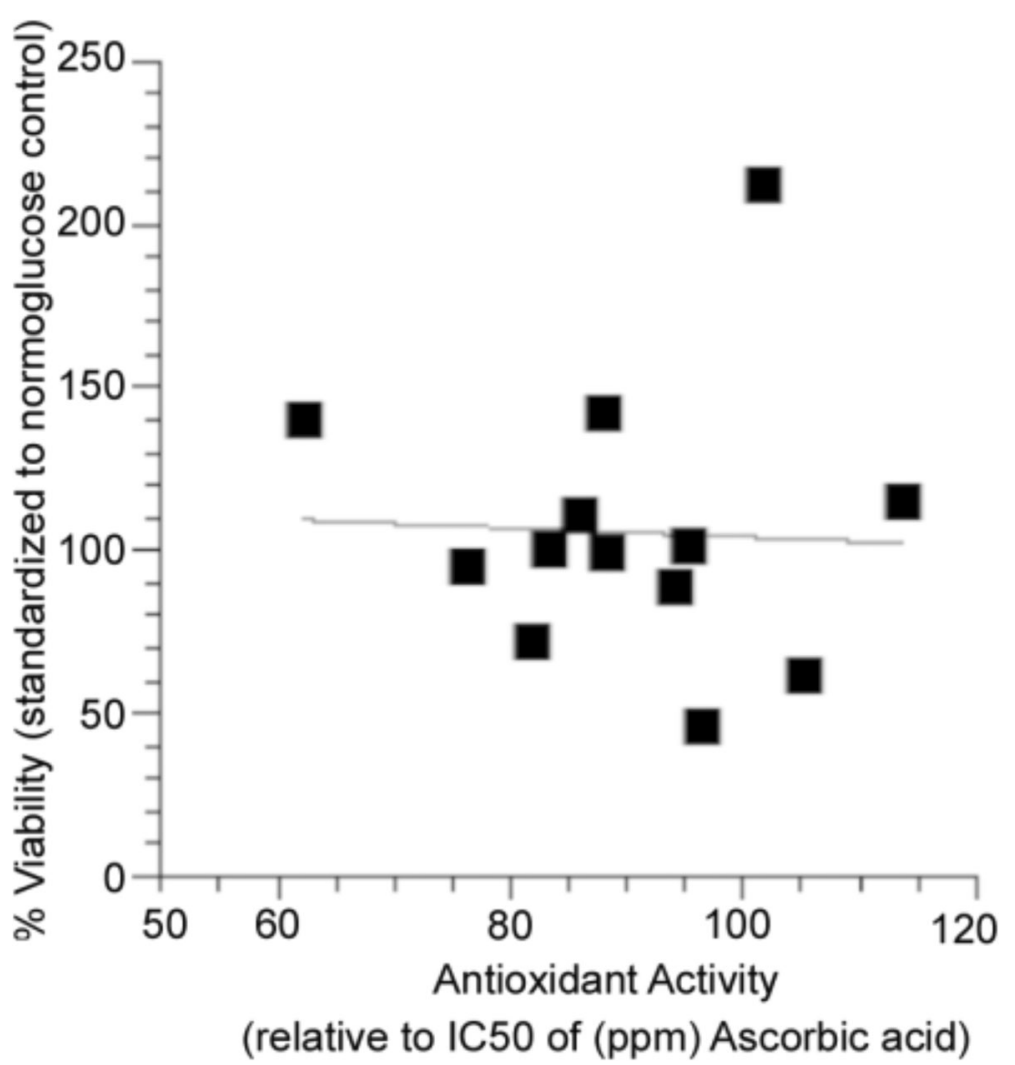

Fig. 7 Regression analysis of antioxidant activity of P. mariana extracts with respect to PC12-AC bioactivity in high glucose media. Antioxidant activity is measured with respect to ascorbic acid and bioactivity is represented as percent viability with respect to normoglucose control. We do not see any trend; therefore, the antioxidant activity is not likely the main mechanism of protection $(p=0.89, n=13)$

area and, therefore, decreases the possibility of harmful environmental impacts.

Using UPLC-QTOF method, a total of 14 phenolics and 18 terpenes were detected or tentatively identified in needle, bark and cones extracts. Among these phenolics, piceatannol was detected in cone and needle extracts, yet absent from bark extract. On the other hand, the identities of resveratrol and isorhapontigenin were only confirmed in the cone extract. These three compounds belong to a group of compounds called stilbenes and have shown a wide range of biological activities such as antidiabetic, antioxidant, anti-aging, anti-cancer and anti-inflammatory activities [33-36]. Of note, resveratrol, is the most studied stilbene and is a known cytoprotector found in red wine [37] while isorhapontigenin is a novel stilbene that was recently identified in red wine. Stilbenes were previously detected in a number of unrelated gymnosperm and angiosperm species such as Abies, Picea, Pinus, Juniperus, Rheum and Morus species [38]. Besides the properties or activities listed above, stilbenes have been shown to improve blood circulation and have antimicrobial activities $[38,39]$. Another interesting phenolic group is the proanthocyanidins; they constitute a subclass of flavonoids that has attracted growing attention due to their potential health promoting effects [40]. Procyanidin B3 and Procyanidin B6 are detected in needle, bark and needle extracts. On the other hand, the flavanonols dihydroquercetin or taxifolin was only confirmed in the cone extract but may nonetheless contribute to cytoprotective effects elicited by these extracts (Additional file 5: Figure S5). Concerning terpenes, the conifer biomarkers abietic and dehydroabietic acids as well as 7-Oxodehydroabietic acid were detected in the extracts of the three plant parts while sandaracopimaric acid was only identified in the needle extract. Importantly, abietic acid and dehydroabietic acid were reported to exhibit a potent inflammatory activity and have antioxidant as well as antiobesity and regulation of glucose metabolism [41]. While still preliminary, this approach can identify the bioactive compounds that underlie species differences as well as reflect the observed growth environment and habitat impact upon extract efficiency.

\section{Conclusion}

$P$. mariana is an effective protector of peripheral neuronal precursor survival when cells are subjected to high glucose conditions. All organs tested in this diabetic neuropathy model (needles, bark and cone) proved to be efficacious. As all organ parts are protective and the 
Table 4 List of compounds in P. mariana needle, bark and cone extracts identified by ESI-QTOF positive electrospray ionization. C (Retention time match $\pm 0.02 \mathrm{~min}$, low and high energy spectra match within $\pm 5 \mathrm{ppm}$ mass accuracy); $\mathrm{P}$ (low and high energy spectra match within 5 ppm mass accuracy); $T$ (signal intensity of quasi molecular ion below 1500 counts); A (absent)

\begin{tabular}{|c|c|c|c|c|c|c|c|c|}
\hline \# & Compound & Molecular formula & Accurate mass & {$[\mathrm{M}+\mathrm{H}]^{+1}$} & Rt. (min) & Needle & Bark & Cone \\
\hline \multicolumn{9}{|c|}{ Phenolics } \\
\hline 1 & 3',4'-Dihydroxyacetophenone & $\mathrm{C} 8 \mathrm{H} 8 \mathrm{O} 3$ & 152.0473 & 153.0553 & 2.71 & C & C & A \\
\hline 2 & 4-Hydroxybenzoic acid & $\mathrm{C} 7 \mathrm{H} 6 \mathrm{O} 3$ & 138.0317 & 139.0396 & 2.66 & C & $\mathrm{T}$ & $\mathrm{T}$ \\
\hline 3 & 4-Methylcatechol & $\mathrm{C} 7 \mathrm{H} 8 \mathrm{O} 2$ & 124.0524 & 125.0604 & 2.98 & $\mathrm{~T}$ & $\mathrm{~T}$ & $\mathrm{~T}$ \\
\hline 4 & Coumarin & $\mathrm{C} 9 \mathrm{H} 6 \mathrm{O} 2$ & 146.0368 & 147.0447 & 2.95 & C & C & A \\
\hline 5 & Dihydroquercetin & $\mathrm{C} 15 \mathrm{H} 12 \mathrm{O} 7$ & 304.0583 & 305.0662 & 3.00 & A & $\mathrm{T}$ & C \\
\hline 6 & Isorhapontigenin & $\mathrm{C} 15 \mathrm{H} 14 \mathrm{O} 4$ & 258.0892 & 259.0971 & 3.11 & $\mathrm{~T}$ & A & C \\
\hline 7 & Isorhapontigenin 3-O-beta-D-glucopyranoside & $\mathrm{C} 21 \mathrm{H} 24 \mathrm{O} 9$ & 420.1420 & 421.1500 & 3.12 & A & A & $P$ \\
\hline 8 & Kaempferol & $\mathrm{C} 15 \mathrm{H} 10 \mathrm{O} 6$ & 286.0477 & 287.0557 & 3.08 & A & A & C \\
\hline 9 & Kaempferol 3-(3"-p-coumaryl-6"-ferulylglucoside) & $\mathrm{C} 40 \mathrm{H} 34 \mathrm{O} 16$ & 770.1847 & 771.1926 & 3.74 & $\mathrm{P}$ & A & A \\
\hline 10 & Kaempferol-7-O-glucoside & $\mathrm{C} 21 \mathrm{H} 20 \mathrm{O} 11$ & 448.1006 & 449.1085 & 2.94 & C & A & A \\
\hline 11 & Piceatannol & $\mathrm{C} 14 \mathrm{H} 12 \mathrm{O} 4$ & 244.0736 & 245.0815 & 2.91 & C & A & C \\
\hline 12 & Procyanidin B3 & $\mathrm{C} 30 \mathrm{H} 26 \mathrm{O} 12$ & 578.1424 & 579.1504 & 3.92 & C & C & C \\
\hline 13 & Procyanidin B6 & $\mathrm{C} 30 \mathrm{H} 26 \mathrm{O} 12$ & 578.1424 & 579.1504 & 2.65 & C & C & C \\
\hline 14 & Resveratrol & $\mathrm{C} 14 \mathrm{H} 12 \mathrm{O} 3$ & 228.0786 & 229.0866 & 3.04 & $\mathrm{~T}$ & A & C \\
\hline \multicolumn{9}{|c|}{ Terpenes } \\
\hline 15 & Picealactone C & $\mathrm{C} 2 \mathrm{OH} 22 \mathrm{O} 4$ & 326.1518 & 327.1597 & 3.58 & A & $P$ & A \\
\hline 16 & Isolariciresinol & $\mathrm{C} 2 \mathrm{OH} 24 \mathrm{O} 6$ & 360.1573 & 361.1652 & 3.70 & $P$ & A & A \\
\hline 17 & Picealactone A & $\mathrm{C} 2 \mathrm{OH} 22 \mathrm{O} 3$ & 310.1569 & 311.1648 & 4.48 & A & $P$ & $\mathrm{~T}$ \\
\hline 18 & Dehydroabietic acid & $\mathrm{C} 2 \mathrm{OH} 28 \mathrm{O} 2$ & 300.2089 & 301.2169 & 3.91 & C & C & C \\
\hline 19 & 12-Hydroxydehydroabietic acid & $\mathrm{C} 2 \mathrm{OH} 28 \mathrm{O} 3$ & 316.2038 & 317.2118 & 4.37 & $P$ & P & $P$ \\
\hline 20 & Abieta-8,11,13-trien-7-one & $\mathrm{C} 2 \mathrm{OH} 28 \mathrm{O}$ & 284.2140 & 285.2219 & 4.19 & $A$ & $P$ & $P$ \\
\hline 21 & 7-Oxodehydroabietic acid & $\mathrm{C} 2 \mathrm{OH} 26 \mathrm{O} 3$ & 314.1882 & 315.1961 & 4.42 & C & C & C \\
\hline 22 & Abietic acid & $\mathrm{C} 2 \mathrm{OH} 30 \mathrm{O} 2$ & 302.2246 & 303.2325 & 4.97 & C & C & C \\
\hline 23 & Sandaracopimaric acid & $\mathrm{C} 2 \mathrm{OH} 30 \mathrm{O} 2$ & 302.2246 & 303.2325 & 4.52 & C & C & A \\
\hline 24 & Typhasterol & $\mathrm{C} 28 \mathrm{H} 48 \mathrm{O} 4$ & 448.3553 & 449.3632 & 5.20 & P & A & A \\
\hline 25 & (+)-Picealactone B & $\mathrm{C} 2 \mathrm{OH} 22 \mathrm{O} 4$ & 326.1518 & 327.1597 & 3.15 & $P$ & A & A \\
\hline 26 & $(+)$-Lariciresinol & $\mathrm{C} 2 \mathrm{OH} 24 \mathrm{O} 6$ & 360.1573 & 361.1652 & 3.73 & $P$ & A & A \\
\hline 27 & Gibberellin A1 & $\mathrm{C} 19 \mathrm{H} 24 \mathrm{O} 6$ & 348.1573 & 349.1652 & 4.63 & $P$ & A & $\mathrm{T}$ \\
\hline 28 & Gibberellin A15 & $\mathrm{C} 2 \mathrm{OH} 26 \mathrm{O} 4$ & 330.1831 & 331.1910 & 3.83 & $P$ & P & $P$ \\
\hline 29 & Gibberellin A51 & $\mathrm{C} 19 \mathrm{H} 24 \mathrm{O} 5$ & 332.1624 & 333.1703 & 4.01 & $P$ & $P$ & $P$ \\
\hline 30 & Gibberellin A29 & $\mathrm{C} 19 \mathrm{H} 24 \mathrm{O} 6$ & 348.1573 & 349.1652 & 4.66 & $\mathrm{P}$ & A & $\mathrm{T}$ \\
\hline 31 & Gibberellin A7 & $\mathrm{C} 19 \mathrm{H} 22 \mathrm{O} 5$ & 330.1467 & 331.1546 & 3.10 & $\mathrm{~T}$ & A & P \\
\hline 32 & Neocembrene & $\mathrm{C} 2 \mathrm{OH} 32$ & 272.2504 & 273.2583 & 5.12 & A & A & $P$ \\
\hline
\end{tabular}

boreal forest of Canada is highly populated by this tree species, we believe $P$. mariana is an excellent candidate for a renewable source of medicine. Further in vitro investigations are necessary to elucidate the underlying mechanisms of action and phenolic variation. In vivo tests using diabetes specific animal models are also needed to confirm that bioactivity remains upon ingestion. Of course, the successful application of this study's findings will also depend on the continuation of an already interdependent relationship developed by the TAAM team, health care professionals and the Eeyou Istchee communities. As the bonds we have built are strong, we are confident that not only $P$. mariana but many of the plants from the Cree pharmacopeia will become part of a new holistic form of diabetes treatment, culturally acceptable to the Cree of Eeyou Istchee and supported by traditional practice and evidence-based inquiry. 


\section{Additional files}

Additional file 1: Figure S1. (A-T). Comparison of cytoprotective, mitogenic and cytotoxic activities of $P$. mariana pooled needle extracts from forest and bog populations in a PC12-AC model of high glucose stress. Populations are listed in ascending order from coastal west [1] to inland east [21] with forest (F) and bog (B) populations next to one another for comparison. Organ type is specified as the last number in the code; needle (N). Therefore, each graph has a code identifying population number, habitat type and organ type above it in that order. Bioactivity was assessed using the formazan dye WST which measures mitochondrial dehydrogenase activity. Treatment wells containing extract were standardized to the normoglucose control $(\mathrm{C})$ and compared to this and the high glucose control $(\mathrm{HG})$ for the determination of protective, mitogenic or toxic effects. A students t-test was used in order to determine the significant difference between the normoglucose control (100\%) and the high glucose control (56.799\%, $n=54$ wells/condition, bar graph, $p \leq$ $0.05)$. Anova analysis was employed in order to compare the $\%$ viability for each concentration $0.25,0.50,1.00$ and $2.00 \mu \mathrm{g} / \mathrm{mL}$ to the normoglucose and high glucose controls. Differences were deemed significant ( ${ }^{*}$ cytoprotection, \#mitogenic) when $p \leq 0.05$ ( $n=3$ treatment wells/concentration). (PDF 973 kb)

Additional file 2: Figure S2. (A-I). Comparison of cytoprotective, mitogenic and cytotoxic activities of $P$. mariana pooled bark extracts from forest and bog populations in a PC12-AC model of high glucose stress. Populations are listed in ascending order from coastal west [1] to inland east [14] with forest (F) and bog (B) populations next to one another for comparison. Organ type is specified as the last number in the code; bark (B). Therefore each graph has a code identifying population number, habitat type and organ type above it in that order. Bioactivity was assessed using the formazan dye WST which measures mitochondrial dehydrogenase activity. Treatment wells containing extract were standardized to the normoglucose control $(C)$ and compared to this and the high glucose control $(\mathrm{HG})$ for the determination of protective, mitogenic or toxic effects. A students t-test was used in order to determine the significant difference between the normoglucose control (100\%) and the high glucose control $(56.799 \%, n=54$ wells/condition, bar graph, $p \leq$ 0.05). Anova analysis was employed in order to compare the $\%$ viability for each concentration $0.25,0.50,1.00$ and $2.00 \mu \mathrm{g} / \mathrm{mL}$ to the normoglucose and high glucose controls. Differences were deemed significant ( ${ }^{*}$ cytoprotection, \#mitogenic) when $\mathrm{p} \leq 0.05$ ( $n=3$ treatment wells/concentration). (PDF $476 \mathrm{~kb}$ )

Additional file 3: Figure S3. (A-F). Comparison of cytoprotective, mitogenic and cytotoxic activities of $P$. mariana pooled cone extracts from bog populations in a PC12-AC model of high glucose stress. Populations are listed in ascending order from coastal west [3] to inland east [15] Habitat is the second letter in the code (bog = B) while Organ type is specified as the last number in the code $($ cone $=C)$. Therefore each graph has a code identifying population number, habitat type and organ type above it in that order. Bioactivity was assessed using the formazan dye WST which measures mitochondrial dehydrogenase activity. Treatment wells containing extract were standardized to the normoglucose control (C) and compared to this and the high glucose control $(\mathrm{HG})$ for the determination of protective, mitogenic or toxic effects. A students t-test was used in order to determine the significant difference between the normoglucose control (100\%) and the high glucose control $(56.799 \%, n=54$ wells/condition, bar graph, $p \leq 0.05)$. Anova analysis was employed in order to compare the $\%$ viability for each concentration $0.25,0.50,1.00$ and $2.00 \mu \mathrm{g} / \mathrm{mL}$ to the normoglucose and high glucose controls. Differences were deemed significant ( ${ }^{*}$ cytoprotection, \#mitogenic) when $p \leq$ 0.05 ( $n=3$ treatment wells/concentration). (PDF $171 \mathrm{~kb}$ )

Additional file 4: Figure S4. (A-B). Chemical structures of compounds in P. mariana needles, bark and cone extracts identified by ESI-QTOF positive electrospray ionization. (A) Phenolics, (B) Terpenes. 1: 3',4'-Dihydroxyacetophenone, 2: 4-Hydroxybenzoic acid, 3: 4-Methylcatechol, 4: Coumarin, 5: Dihydroquercetin, 6: Isorhapontigenin, 7: Isorhapontigenin 3-O-beta-Dglucopyranoside, 8: Kaempferol, 9: Kaempferol 3-(3"-p-coumaryl-6"-ferulylglucoside), 10: Kaempferol-7-O-glucoside, 11: Piceatannol, 12: Procyanidin B, 13: Procyanidin B6, 14: Resveratrol, 15: Picealactone C, 16:
Isolariciresinol, 17: Picealactone A, 18: Dehydroabietic acid, 19: 12 Hydroxydehydroabietic acid, 20: Abieta-8,11,13-trien-7-one, 21: 7Oxodehydroabietic acid, 22: Abietic acid, 23: Sandaracopimaric acid, 24: Typhasterol, 25: (+)-Picealactone B, 26: (+)-Lariciresinol, 27: Gibberellin A1, 28: Gibberellin A15, 29: Gibberellin A51, 30: Gibberellin A29, 31: Gibberellin A7, 32: Neocembrene. (PDF $131 \mathrm{~kb}$ )

Additional file 5: Figure S5. Total ion chromatograms obtained from (A) needles, (B) bark and (C) cones by ESI-QTOF positive electrospray ionization. (PDF $1006 \mathrm{~kb}$ )

Additional file 6: Figure S6. Taxifolin protects PC12 cells from high glucose-mediated death. Exposure to glucose toxicity produced a significant loss in cell viability compared to normal glucose conditions as assessed by mitochondrial dehydrogenase activity measured by cleavage of the formazan dye WST [left panel, ** denotes a significant difference $(p<0.01)$ relative to normal glucose control, Student's t-test, $n=16]$. Three concentrations of taxifolin $(0.8,1.6$ and $3.2 \mu \mathrm{M})$ were administered to high glucose-treated cells. Cytoprotective activity was assessed as described in methods section. *denote significant differences $(p<0.05)$ between high glucose and taxifolin sample (ANOVA, post-hoc Dunnett's ttest, $n=10-15$ ). Data are reported as the mean \pm SEM. (PDF $618 \mathrm{~kb}$ )

\section{Abbreviations}

ATCC: American Type Culture Collection; DPPH: 1,1-diphenyl-2-picrylhydrazyle radical; SIV: Syndromic Importance Value; UPLC-QTOF MS: UltraPerformance Liquid Chromatography-quadrupole time-of-flight mass spectrometry

\section{Acknowledgements}

We thank Research Associate Ammar Saleem, Lanset Facility University of Ottawa for the identification of compounds using the new UNIFI phytochemical database. Very special thanks are due to Josephine Diamond, Alice Jacob and Jimmy Trapper from Waskaganish First Nation, Isabel Wapachee, Louise Jolly Wapachee, Bessie Blackned, Annie Jolly, Charlie Jolly, Abel Jolly, Alice Ottereyes Jolly, Helen Jolly Metaweskum, Mary Jolly, Helen Jolly Wapachee and Edith Jolly Matoush from Nemaska First Nation, Smally Petawabano, Laurie Petawabano, Charlie Coon, Sophie Coon, Mabel Gunner, Abel Mark, Kathleen Mark, Elizabeth Coon Come, Herriett Matoush, Sandy Matoush, Rene Coon and Emma Coon Come from the Cree Nation of Mistissini and Abraham Mamianskum, Agnes Kawapit, Andrew Natachequan, Anne Sandy, Eliza George Mamianskum, Eliza Kawapit, James Kawapit, Jeanny Masty, John Petagumskum Sr., Lucy Rupert, Maggie Natachequan and Mathew Natachequan from Whapmagoostui First Nation as well as to 66 other Cree Elders from all four communities who kindly agreed to be interviewed but chose not to be specifically mentioned. They made this research possible by allowing us to use their knowledge relating to medicinal plants, transmitted to them by their elders. Their trust has also enabled a useful exchange between indigenous knowledge and western science. We thank Mr. Steven Rennick for his technical assistance.

\section{Authors' contributions}

ADD did the fieldwork, biological activities, data analysis, drafting the paper and participated in sample preparations. HME participated in analysis and interpretation of data, drafting the article and critically revising the manuscript for intellectual content. AT participated in sample preparations and the total phenolics. FA and CSH helped out with the bioactivity assays. AS ran the UPLC-QTOF analysis. PSH, JTA and SALB collaborated by providing precious professional advice for the experimental protocols as well as revising the manuscript. TJ is the co-supervisor and $A C$ is the supervisor and the corresponding author. AC also helped with the fieldwork. All co-authors read and approved the final manuscript.

\section{Funding}

This study was supported by a CIHR Team Grant in Aboriginal Antidiabetic Medicines (MOP 62826) to SALB, AC, JTA, TJ, and PSH.

\section{Availability of data and materials}

The data and materials used in this study are available from the corresponding author on request. 


\section{Ethics approval and consent to participate}

Not applicable.

\section{Consent for publication}

Not applicable.

\section{Competing interests}

The authors declare that they have no competing interests.

\section{Author details}

${ }^{1}$ Jardin botanique de Montreal, Institut de recherche en biologie végétale, Université de Montréal, 4101, rue Sherbrooke Est, Montreal, (Québec) H1X 2B2, Canada. ${ }^{2}$ Department of Pharmacology, Natural Health Products and Metabolic Diseases Laboratory, Université de Montréal, Montreal, QC, Canada. ${ }^{3}$ Department of Pharmacognosy, Faculty of Pharmacy, Beni-Suef University, Beni-Suef, Egypt. ${ }^{4}$ Department of Biology, Laboratory for the Analysis of Natural and Synthetic Environmental Toxins, University of Ottawa, Ottawa, ON, Canada. ${ }^{5}$ School of Dietetics and Human Nutrition, McGill University, Montreal, Canada. ${ }^{6}$ Department of Biochemistry, Microbiology, and Immunology " University of Ottawa, Ottawa, Canada.

\section{Received: 30 October 2018 Accepted: 5 June 2019}

\section{Published online: 18 June 2019}

\section{References}

1. Newbold KB. Problems in search of solutions: health and Canadian aboriginals. J Community Health. 1998;23(1):59-73.

2. Tookenay VF. Improving the health status of aboriginal people in Canada: new directions, new responsibilities. CMAJ. 1996;155(11):1581-3.

3. Young TK, Reading J, Elias B, O'Neil JD. Type 2 diabetes mellitus in Canada's first nations: status of an epidemic in progress. CMAJ. 2000;163(5):561-6.

4. Canada H. Diabetes in Canada; National Statistics and Opportunities for Improved Surveillance, Prevention and Control. 1999. M.o. Health (Ed.)

5. Canada H. Diabetes Among Aboriginal People in Canada: the Evidence. 2000. M.o Health (Ed.)

6. Boston P, Jordan S, MacNamara E, Kozolanka K, Bobbish-Rondeau E, Iserhoff $\mathrm{H}$, et al. Using participatory action research to understand the meanings aboriginal Canadians attribute to the rising incidence of diabetes. Chronic Dis Can. 1997;18(1):5-12.

7. Marbella AM, Harris MC, Diehr S, Ignace G, Ignace G. Use of native American healers among native American patients in an urban native American health center. Arch Fam Med. 1998;7(2):182-5.

8. Legaré G. Project of diabetes surveillance among the Cree of Eeyou Istchee. 2004. I.N.D.S.P.d. Quebec (Ed.).

9. Reagan AB. Plants used by the bois fort Chippewa (Ojibwa) Indians of Minnesota. Milwaukee: Wisconsin Archeologist; 1928. p. 230-48.

10. Smith HH. Ethnobotany of the forest potawatomi indians. Bull Public Mus City Milw. 1933;7:1-230.

11. Leighton AL. Wild Plant Use by the Woods Cree (Nihithawak) of East-Central Saskatchewan. Ottawa: Mercury Series; 1985. NMo, editor

12. Nilson Richard K. Make prayers to the raven--a Koyukon view of the northern Forest. Chicago: The University of Chicago Press; 1983.

13. Letendre AD. Aboriginal traditional medicine: where does it fit? Crossing boundaries. Interdiscip J. 2002;1(2):78-87.

14. Fraser MH, Cuerrier A, Haddad PS, Arnason JT, Owen PL, Johns T. Medicinal plants of Cree communities (Quebec, Canada): antioxidant activity of plants used to treat type 2 diabetes symptoms. Can J Physiol Pharmacol. 2007;85(11):1200-14.

15. Leduc C, Coonishish J, Haddad P, Cuerrier A. Plants used by the Cree nation of Eeyou Istchee (Quebec, Canada) for the treatment of diabetes: a novel approach in quantitative ethnobotany. J Ethnopharmacol. 2006;105(1-2):55-63.

16. Downing AA. Inter and intra-specific differences in medicinal plant use for the treatment of type II diabetes symptoms by the Cree elders of Eeyou Istchee (QC). Montreal: University of Montreal; 2010.

17. Spoor DC, Martineau LC, Leduc C, Benhaddou-Andaloussi A, Meddah B, Harris $C$, et al. Selected plant species from the Cree pharmacopoeia of northern Quebec possess anti-diabetic potential. Can J Physiol Pharmacol. 2006;84(8-9):847-58

18. Harris CS, Beaulieu LP, Fraser MH, Mclntyre KL, Owen PL, Martineau LC, et al Inhibition of advanced glycation end product formation by medicinal plant extracts correlates with phenolic metabolites and antioxidant activity. Planta Med. 2011;77(2):196-204.
19. Harris CS, Lambert J, Saleem A, Coonishish J, Martineau LC, Cuerrier A, et al. Antidiabetic activity of extracts from needle, bark, and cone of Picea glauca.: organ-specific protection from glucose toxicity and glucose deprivation. Pharm Biol. 2008:46(1-2):126-34.

20. Brewer C, Bonin F, Bullock P, Nault MC, Morin J, Imbeault S, et al. Platelet activating factor-induced apoptosis is inhibited by ectopic expression of the platelet activating factor G-protein coupled receptor. J Neurochem. 2002;82(6):1502-11.

21. Harris CS, Mo F, Migahed L, Chepelev L, Haddad PS, Wright JS, et al. Plant phenolics regulate neoplastic cell growth and survival: a quantitative structureactivity and biochemical analysis. Can J Physiol Pharmacol. 2007;85(11):1124-38.

22. Harris CS, Asim M, Saleem A, Haddad PS, Arnason JT, Bennett SA. Characterizing the cytoprotective activity of Sarracenia purpurea L., a medicinal plant that inhibits glucotoxicity in PC12 cells. BMC Complement Altern Med. 2012;12:245.

23. Owen PL, Johns T. Antioxidants in medicines and spices as Cardioprotective agents in Tibetan highlanders. Pharm Biol. 2002;40(5):346-57.

24. Singleton VL, Rossi JA. Colorimetry of total phenolics with phosphomolybdicphosphotungstic acid reagents. Am J Enol Vitic. 1965;16(3):144-58.

25. Salehi B, Mishra AP, Nigam M, Sener B, Kilic M, Sharifi-Rad M, et al. Resveratrol: a double-edged sword in health benefits. Biomedicines. 2018;6(3):91. https://doi. org/10.3390/biomedicines6030091

26. Xie X, Feng J, Kang Z, Zhang S, Zhang L, Zhang Y, et al. Taxifolin protects RPE cells against oxidative stress-induced apoptosis. Mol Vis. 2017;23:520-8.

27. Kuzmina E, Lejeune P, Dannenbaum D and Torrie J. Cree Diabetes Information System (CDIS) 2007 Annual report. Public Health Report Series 3 on diabetes. Cree Board of Health and Social Services of James Bay. 2008. Québec, ISNN: 1712-9249.

28. Rapinski M, Musallam L, Arnason JT, Haddad P, Cuerrier A. Adipogenic activity of wild populations of rhododendron groenlandicum, a medicinal shrub from the James Bay Cree traditional pharmacopeia. Evid Based Complement Alternat Med. 2015;2015:492458.

29. Rapinski M, Liu R, Saleem A, Arnason JT, Cuerrier A. Environmental trends in the variation of biologically active phenolic compounds in Labrador tea, Rhododendron groenlandicum, from northern Quebec, Canada. Botany. 2014;92(11):783-94.

30. Diouf PN, Stevanovic T, Cloutier A. Study on chemical composition, antioxidant and anti-inflammatory activities of hot water extract from Picea mariana bark and its proanthocyanidin-rich fractions. Food Chem. 2009;113(4):897-902.

31. Marles RJ, Clavelle C, Monteleone L, Tays N, Burn D. Aboriginal plant use in Canada's northwest boreal forest. Natural Resources Canada CFS, northern forestry Centre, Edmonton, Alberta. Vancouver: UBC Press; 2008.

32. Martineau LC, Adeyiwola-Spoor DC, Vallerand D, Afshar A, Arnason JT, Haddad PS. Enhancement of muscle cell glucose uptake by medicinal plant species of Canada's native populations is mediated by a common, metformin-like mechanism. J Ethnopharmacol. 2010;127(2):396-406.

33. Kukreja A, Wadhwa N, Tiwari A. Therapeutic role of resveratrol and Piceatannol in disease prevention. J Blood Disord Transfus. 2014;5(240):9.

34. Liu Y, Liu G. Isorhapontigenin and resveratrol suppress oxLDL-induced proliferation and activation of ERK1/2 mitogen-activated protein kinases of bovine aortic smooth muscle cells. Biochem Pharmacol. 2004;67(4):777-85.

35. Li HL, Wang AB, Huang Y, Liu DP, Wei C, Williams GM, et al. Isorhapontigenin, a new resveratrol analog, attenuates cardiac hypertrophy via blocking signaling transduction pathways. Free Radic Biol Med. 2005; 38(2):243-57.

36. Oritani Y, Okitsu T, Nishimura E, Sai M, Ito T, Takeuchi S. Enhanced glucose tolerance by intravascularly administered piceatannol in freely moving healthy rats. Biochem Biophys Res Commun. 2016;470(3):753-8.

37. Fremont L. Biological effects of resveratrol. Life Sci. 2000;66(8):663-73.

38. Chrząścik I. Analysis of biologically active stilbene derivatives. Crit Rev Anal Chem. 2009:39:70-80

39. Reinisalo M, Karlund A, Koskela A, Kaarniranta K, Karjalainen RO. Polyphenol stilbenes: molecular mechanisms of Defence against oxidative stress and aging-related diseases. Oxidative Med Cell Longev. 2015;2015:340520.

40. Nollet LML, Toldr. F. Handbook of analysis of active compounds in functional foods. Boca Raton [etc.]: CRC Press/Taylor \& Francis Group; 2012.

41. Goto T, Takahashi N, Hirai S, Kawada T. Various Terpenoids derived from herbal and dietary plants function as PPAR modulators and regulate carbohydrate and lipid metabolism. PPAR Res. 2010;2010:483958.

\section{Publisher's Note}

Springer Nature remains neutral with regard to jurisdictional claims in published maps and institutional affiliations. 